\title{
Gold nanoparticle enrichment method for identifying S-nitrosylation and $S$ - glutathionylation sites in proteins
}

\author{
Adam Faccenda $^{1,{ }_{s}}$, Christopher A. Bonham ${ }^{1, s}$, Panayiotis O. Vacratsis ${ }^{1}$, Xueji Zhang $^{2,3}$ \& Bulent Mutus $^{*, 1}$ \\ ${ }^{I}$ Department of Chemistry \& Biochemistry, University of Windsor, 401 Sunset Ave, Windsor, Ontario, Canada \\ ${ }^{2}$ World Precision Instruments, Sarasota, Florida, 34240 USA \\ ${ }^{3}$ School of Applied Science, University of Science \& Technology, Beijing, No. 30 Xueyuan Rd., Beijing, 100083, P. R. China \\ :These individuals contributed equally to the manuscript.
}

\section{Supporting Information}

I. General Information. Gold (III) chloride trihydrate, trisodium citrate dihydrate, reduced and oxidized glutathione, sodium nitrite, iodoacetamide, N-ethylmaleimide and dithiothreitol were purchased from Sigma. All commercial reagents were used without further purification. Zeba ${ }^{\mathrm{TM}}$ Desalt Spin Columns, trifluoroacetic acid, recrystalized $\alpha$-cyano-4-hydroxycinnamic acid and ascorbic acid were purchased from Thermo Scientific. Siliconized micro-centrifuge tubes were purchased from Bio Plas Inc and were used for all protein processing steps. Sequencing grade Trypsin was purchased from Promega, Endoproteinase Glu-C was purchased from Roche Applied Science. Vivapure C-18 Micro spin columns were purchased from Sartorius Stedim Biotech. High purity water and acetonitrile were purchased from Honeywell Burdick and Jackson.

II. Gold Nanoparticle (AuNP) Synthesis. AuNPs were synthesized according to the method of Grabar et al. ${ }^{1}$. All glassware was washed and rinsed thoroughly with Milli-Q (18.2 M $)$ ) high purity water. In a $1 \mathrm{~L}$ double-neck round bottom flask, $197 \mathrm{mg}$ gold (III) chloride trihydrate $\left(\mathrm{HAuCl}_{4} \cdot 3 \mathrm{H}_{2} \mathrm{O}\right)$ was dissolved in $500 \mathrm{~mL}$ of Milli-Q water and refluxed for $1 \mathrm{~h}$ in a hot-oil bath $\left(\sim 100{ }^{\circ} \mathrm{C}\right)$ with vigorous stirring. Following reflux, $571 \mathrm{mg}$ trisodium citrate dihydrate $\left(\mathrm{Na}_{3} \mathrm{C}_{5} \mathrm{H}_{5} \mathrm{O}_{7} \cdot 2 \mathrm{H}_{2} \mathrm{O}\right)$ was dissolved in $50 \mathrm{~mL}$ Milli-Q water and injected rapidly into the gold chloride solution. A distinct colour change can be seen from yellow to clear, then to dark burgundy (almost black) signifying the formation of a colloidal solution. After $10 \mathrm{~min}$, the heat was removed and the solution was allowed to cool to room temperature. The resulting nanoparticles are $11 \pm 1 \mathrm{~nm}$ in diameter, exhibit a maximum absorbance at 521 $\mathrm{nm}$ and are stable for months at $4{ }^{\circ} \mathrm{C}$. The resulting concentration is $\sim 1.3 \times 10^{10} \mathrm{AuNPs} / \mu \mathrm{L}$.

III. S-nitrosoglutathione (GSNO) Synthesis. All steps were performed in the dark due to the photosensitivity of the SNO bond. $10.3 \mathrm{mg}$ sodium nitrite $\left(\mathrm{NaNO}_{2}\right)$ was dissolved in $4 \mathrm{~mL}$ of ice-cold $0.5 \mathrm{M} \mathrm{HCl} .46 .1 \mathrm{mg}$ of reduced glutathione (GSH) was then dissolved in $1 \mathrm{~mL}$ of ice-cold $0.5 \mathrm{M} \mathrm{HCl}$ and added to the $\mathrm{NaNO}_{2}$ solution. The mixture was incubated in the dark at $4{ }^{\circ} \mathrm{C}$ for 30 min and the $\mathrm{pH}$ was adjusted to 7.4 by the addition of dilute $\mathrm{NaOH}$. GSNO concentration was determined from the absorption maximum of the $\mathrm{SNO}$ bond at $335 \mathrm{~nm}\left(\varepsilon_{335}=980 \mathrm{M}^{-1} \mathrm{~cm}^{-1}\right)$. The resulting solution was stored as $1 \mathrm{~mL}$ aliquots at $-80{ }^{\circ} \mathrm{C}$.

IV. Protein Nitrosylation and Alkylation. Recombinant PDI and hYVH1 were purified as previously described ${ }^{2,3}$. Fully reduced proteins $(2 \mu \mathrm{M})$ were nitrosylated by incubation with $1 \mathrm{mM}$ GSNO in $0.1 \mathrm{M}$ sodium phosphate buffer $(\mathrm{pH} 7.4)$ for $1 \mathrm{~h}$ at room

(1) Grabar, K. C.; Freeman, R. G.; Hommer, M. B.; Natan, M.J. Anal. Chem. 1995, 67, 735-43.

(2) Sliskovic, I.; Raturi, A.; Mutus, B. J. Biol. Chem. 2005, 280, 8733-41.

(3) Bonham, C. A.; Vacratsis, P. O. J. Biol. Chem. 2009, 284, 22853-64. 
temperature. Iodoacetamide (IAM) was then added to a final concentration of $10 \mathrm{mM}$ and incubated for $2 \mathrm{~h}$ at room temperature. Excess GSNO and IAM were removed by two passes through Zeba ${ }^{\mathrm{TM}}$ Desalt Spin Columns as per the manufacturer's specifications. At this step, the buffer was exchanged to $50 \mathrm{mM}$ ammonium bicarbonate ( $\mathrm{pH} \sim 8$, unadjusted).

V. Protein Nitrosylation, Glutathionylation and Differential Alkylation. Fully reduced recombinant hYVH1 (30 $\mu \mathrm{M})$ was nitrosylated or glutathionylated by incubation with $1 \mathrm{mM} \mathrm{GSNO}$ or oxidized glutathione (GSSG) in $25 \mathrm{mM} \mathrm{Tris-HCl} 50 \mathrm{mM}$ NaCl $(\mathrm{pH} 7.5)$ in the dark, shaking for $1 \mathrm{~h}$ at room temperature. Iodoacetamide was then added to a final concentration of $20 \mathrm{mM}$ and incubated in the dark, shaking for $1 \mathrm{~h}$ at room temperature. Both samples were desalted as above, except nitrosylated hYVH1 was exchanged into $25 \mathrm{mM}$ Tris- $\mathrm{HCl} 50 \mathrm{mM} \mathrm{NaCl}$ (pH 7.5) buffer. Ascorbate, N-ethylmaleimide, and copper (II) sulfate were then added to final concentrations of $30 \mathrm{mM}, 20 \mathrm{mM}$, and $300 \mathrm{nM}$ respectively. The sample was incubated in the dark, shaking for $3 \mathrm{~h}$ at room temperature, then desalted as above for subsequent proteolysis.

VI. Proteolytic Digestion. A 10:1 protein:protease (by mass) ratio was maintained for all digests. PDI was digested for $18 \mathrm{~h}$ with Endoproteinase Glu-C shaking at room temperature. hYVH1 was digested for $12 \mathrm{~h}$ with Trypsin shaking at $37^{\circ} \mathrm{C}$. For solution digest spectra, the samples were quenched by a final concentration of $1 \%$ formic acid.

VII. AuNP-Peptide Binding and Elution. AuNPs $(500 \mu \mathrm{L})$ were pelleted by centrifugation $(16,000 \mathrm{x} \mathrm{g}$ for $15 \mathrm{~min})$. The supernatant was discarded and $40 \mu \mathrm{L}$ of unquenched protein digests were added to the AuNP pellet and incubated 30 min at $37^{\circ} \mathrm{C}$. The AuNP-peptide complex was centrifuged, the supernatant was aspirated and the AuNP-peptide pellet was washed in $200 \mu \mathrm{L}$ of $10 \mathrm{mM}$ ammonium bicarbonate ( $\mathrm{pH} \sim 7.6$, unadjusted) three times. After the wash-spin steps the AuNP-bound peptides were then eluted in $20 \mu \mathrm{L}$ of $100 \mathrm{mM}$ dithiothreitol (DTT). Following addition of DTT, the AuNPs were sonicated for 5 min in a water bath to disperse any AuNP aggregates. This was followed by a $2 \mathrm{~h}$ incubation after which the AuNPs were again pelleted and the supernatant harvested. To ensure the complete elution of peptides from the AuNP surface, a second addition of $20 \mu \mathrm{L}$ of $100 \mathrm{mM}$ DTT was incubated with the AuNPs for $8 \mathrm{~h}$ with gentle agitation. The AuNPs were centrifuged and the resulting supernatant was combined with that from the first DTT elution step. Samples were acidified by the addition of $100 \mu \mathrm{L} 0.1 \%$ trifluoroacetic acid, then desalted and concentrated using Vivapure C-18 Micro spin columns as per the manufacturer's protocol. All digests were mixed 1:1 with $10 \mathrm{mg} / \mathrm{mL}$ matrix solution (recrystalized $\alpha$-cyano-4-hydroxycinnamic acid in $60 \%$ acetonitrile, $0.1 \%$ trifluoroacetic acid) on the target plate by dried droplet method and analyzed by MALDI-TOF MS using an Applied Biosystems Voyager DE-Pro Mass Spectrometer. Peptide mass fingerprints and tandem mass spectrometry (MS/MS) using post source decay (PSD) was performed on selected parent ions as previously described ${ }^{3}$ and compared to in silico fragmentation using the Protein Prospector software (http://prospector.ucsf.edu/). 


$\begin{array}{clcc}\text { Residue } & \text { Sequence } & \begin{array}{c}\text { Monoisotopic } \\ (\mathbf{m} / \mathbf{z})\end{array} & \begin{array}{c}\text { IAM } \\ \text { (+ 57 } \mathbf{~ D a})\end{array} \\ 325-331 & \text { FCHRFLE } & 951.5 & 1008.5 \\ 31-45 & \text { FYAPWCGHCKALAPE } & 1692.7 & 1749.7 / 1806.7 \\ 287-306 & \text { FFGLKKEECPAVRLITLEEE } & 2351.2 & 2408.2 \\ 374-394 & \text { FYAPWCGHCKQLAPIWDKLGE } & 2462.2 & 2519.2 / 2576.2\end{array}$

Table S1. Protein disulfide isomerase thiol-containing peptides. Mass fingerprint reference table of target thiolcontaining peptides from recombinant protein digest using Endoproteinase Glu-C.

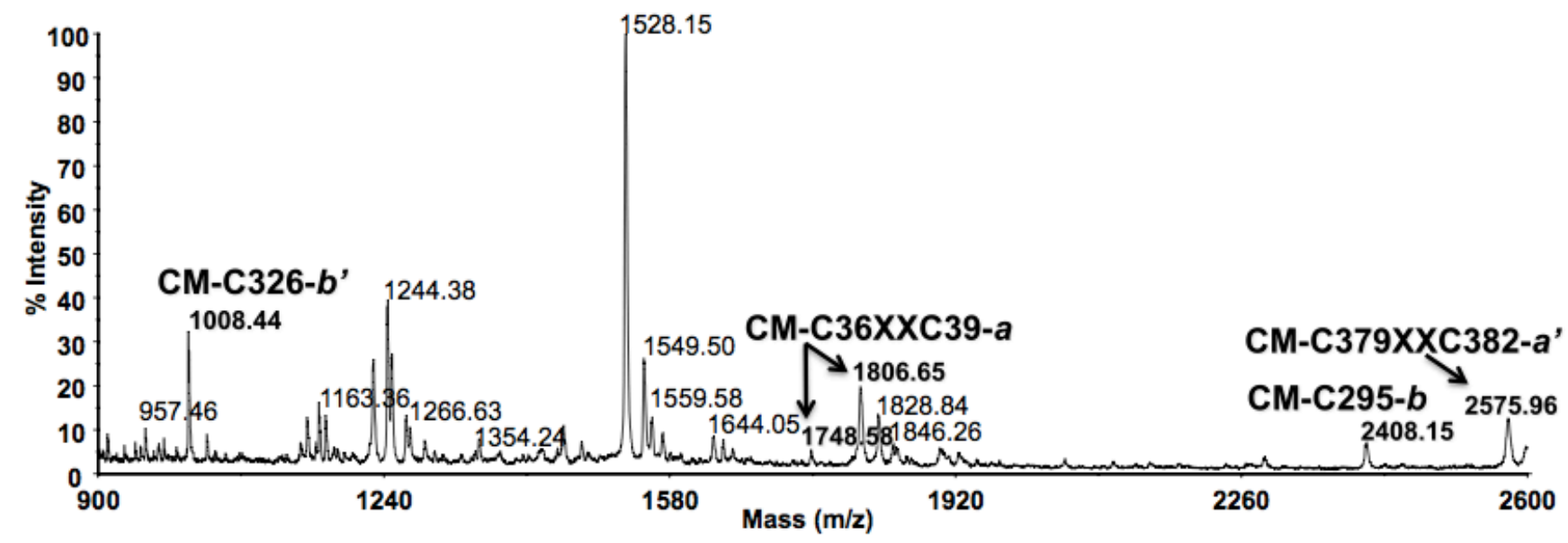

Figure S1. Mass fingerprint of reduced, CM-labeled, Endoproteinase Glu-C digested PDI (no AuNPs). Modified thiol-containing peptides are highlighted, their peptide masses in bold. 


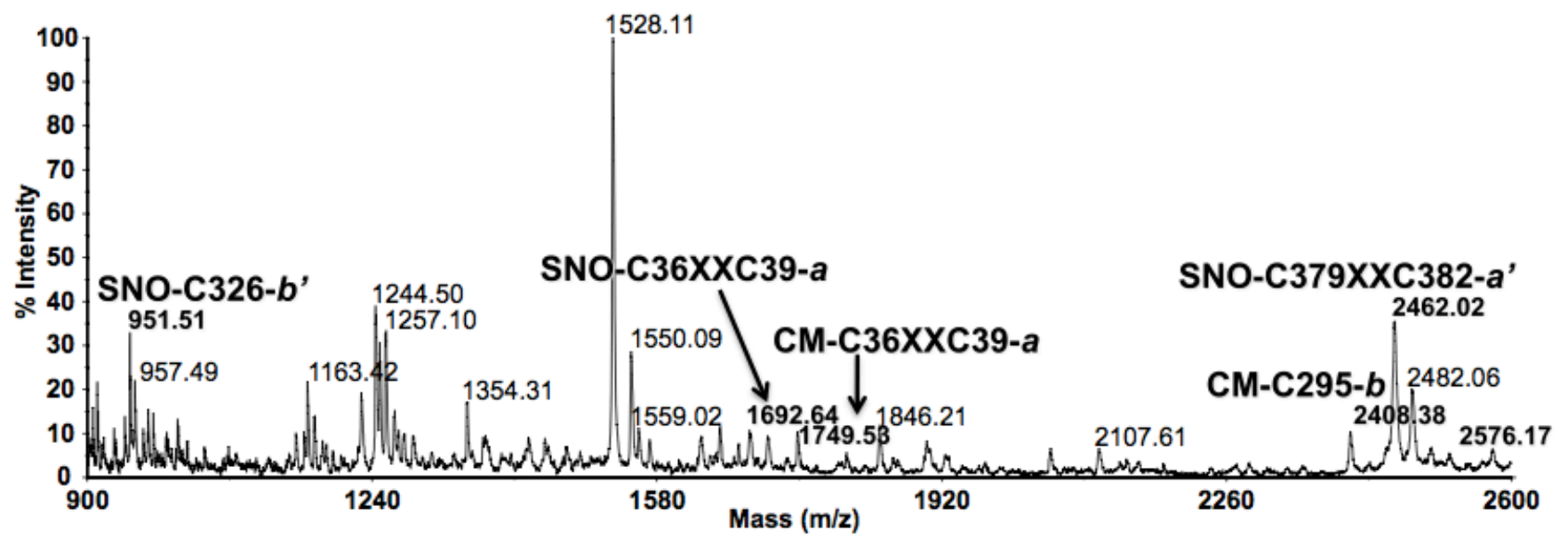

Figure S2. Mass fingerprint of reduced, $S$-nitrosylated, CM-labeled, Endoproteinase Glu-C digested PDI (no AuNPs). Modified thiol-containing peptides are highlighted, their peptide masses in bold.

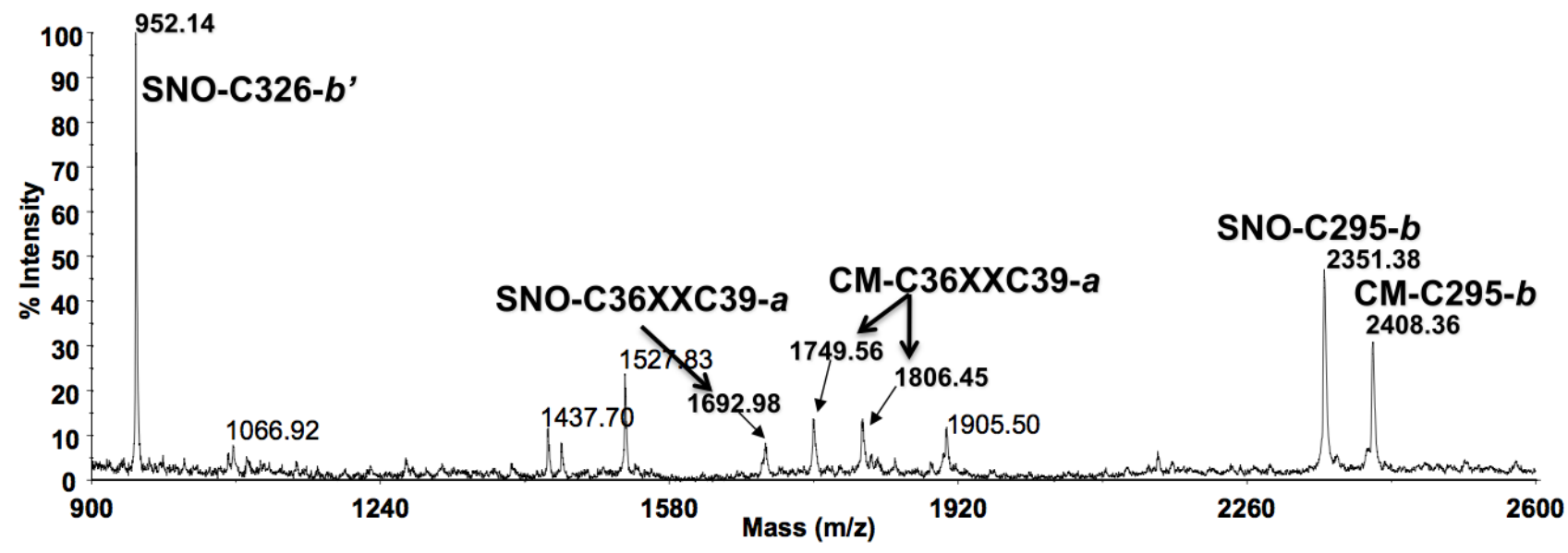

Figure S3. Mass fingerprint of reduced, $S$-nitrosylated, CM-labeled, Endoproteinase Glu-C digested, AuNPbound PDI DTT elution. Modified thiol-containing peptides are highlighted, their peptide masses in bold. 


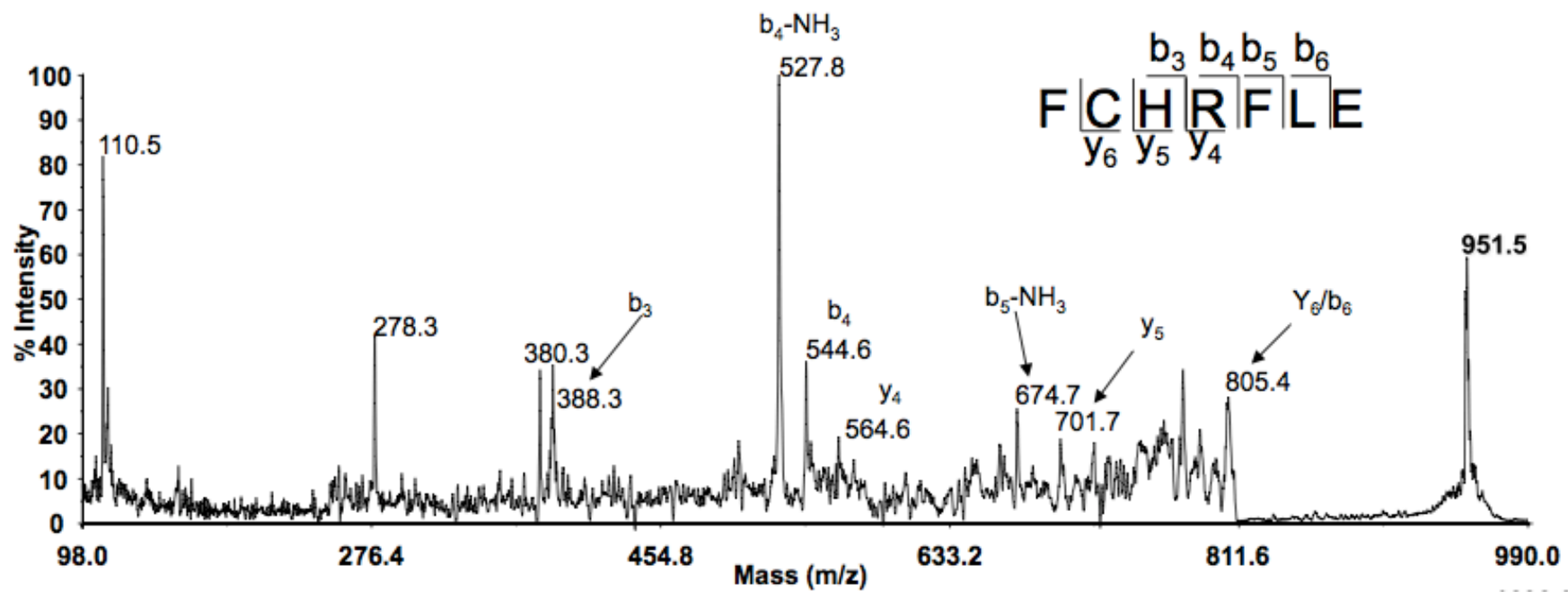

Figure S4. MS/MS analysis of PDI $\boldsymbol{b}$ ' domain parent ion peak $\mathrm{m} / \mathrm{z} 951.5$ from reduced, $S$-nitrosylated, CMlabeled, Endoproteinase Glu-C digested, AuNP-bound DTT elution sample.

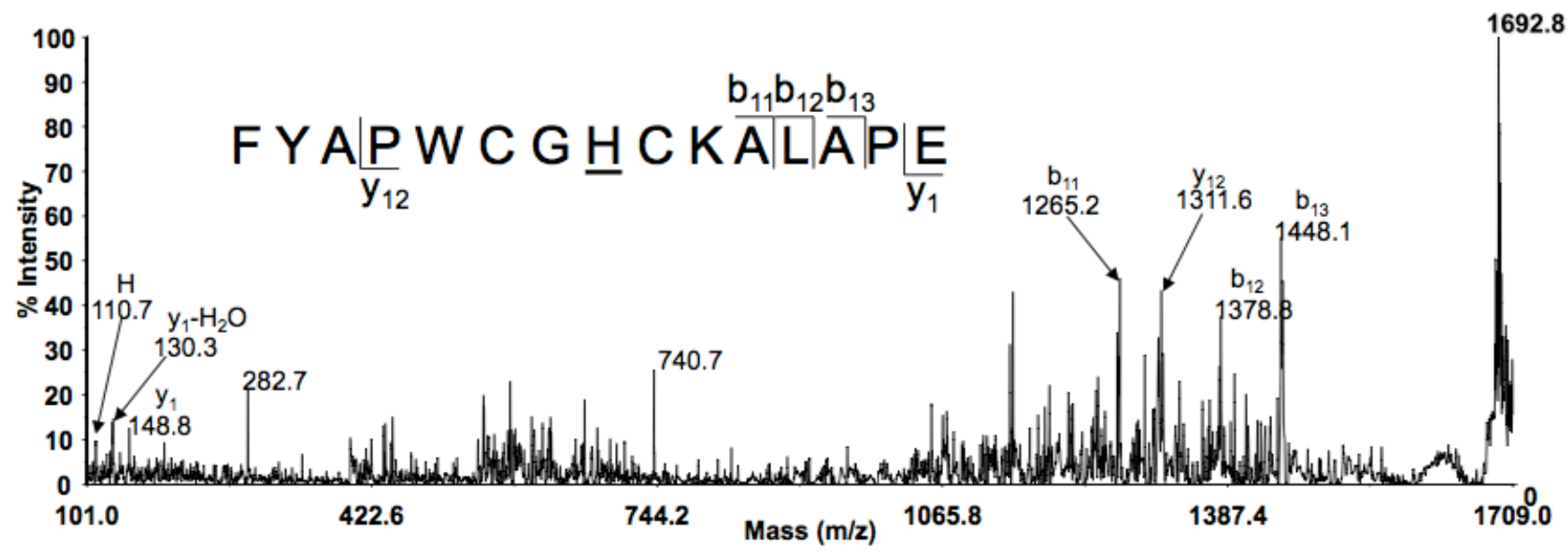

Figure S5. MS/MS analysis of PDI $\boldsymbol{a}$ domain parent ion peak $m / z 1692.8$ from reduced, $S$-nitrosylated, CMlabeled, Endoproteinase Glu-C digested, AuNP-bound DTT elution sample. 


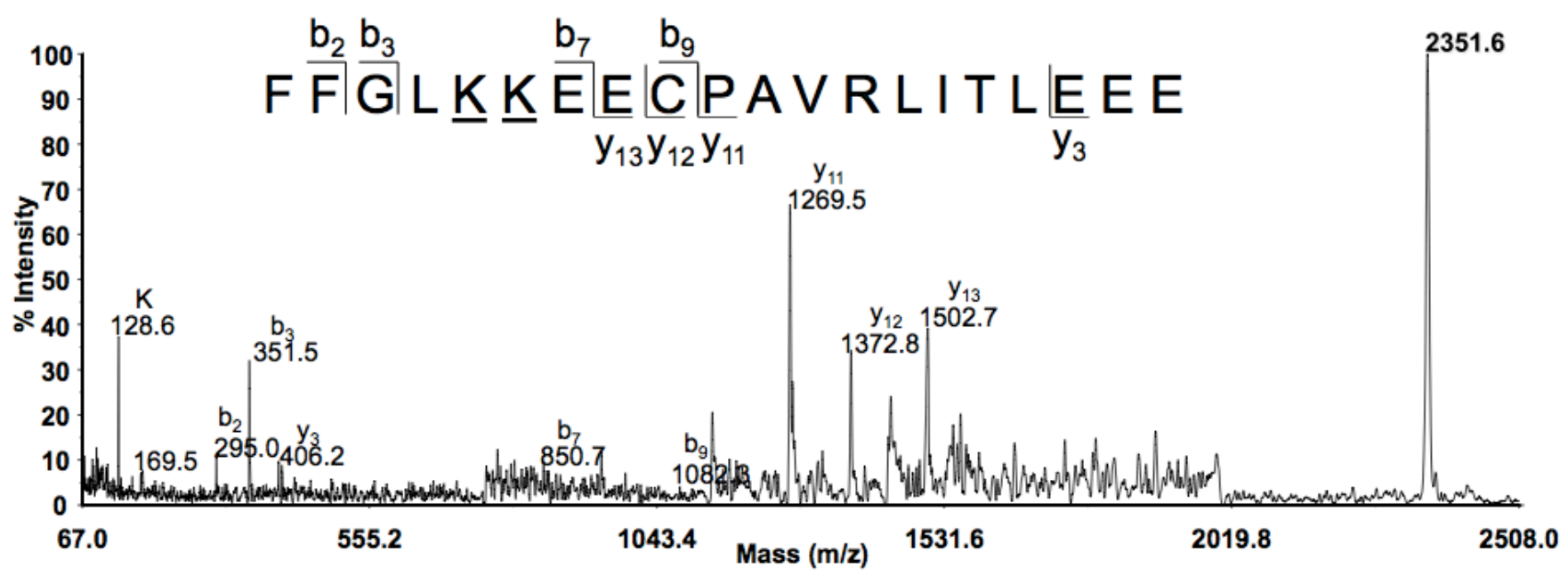

Figure S6. MS/MS analysis of PDI $\boldsymbol{b}$ domain parent ion peak $\mathrm{m} / z$ 2351.6 from reduced, $S$-nitrosylated, CMlabeled, Endoproteinase Glu-C digested, AuNP-bound DTT elution sample. 


\begin{tabular}{|c|c|c|c|c|c|}
\hline Residue & Sequence & $\begin{array}{l}\text { Monoisotopic } \\
(\mathrm{m} / \mathrm{z})\end{array}$ & ic $\begin{array}{c}\text { IAM } \\
(+57 \mathrm{Da})\end{array}$ & $\begin{array}{c}\text { NEM } \\
\text { (+ } 125 \mathrm{Da})\end{array}$ & $\begin{array}{c}\text { GSSG } \\
\text { (+ 305 Da) }\end{array}$ \\
\hline $102-110$ & CVAFIGQAR & 964.5 & 1021.5 & 1089.6 & 1269.5 \\
\hline $115-126$ & AVLVHCHAGVSR & 1248.7 & 1305.7 & 1373.7 & 1553.7 \\
\hline $302-316$ & LGSFNWYGEQCSCGR & 1706.7 & $1763.7 / 1820.7$ & 1831.8/1956.8 & 2011.7/2316.7 \\
\hline $1-25$ & GSPEFMLEAPGPSDGCELSN & 2535.1 & 2592.1 & 2660.2 & 2840.1 \\
\hline $26-54$ & VSCAGQMLEVQPGLYFGGAAAVAEPDHLR & R $\quad 2986.5$ & 3043.5 & 3111.5 & 3291.5 \\
\hline
\end{tabular}

Table S2. Human YVH1 thiol-containing peptides. Mass fingerprint reference table of target thiol-containing peptides from recombinant protein digest using Trypsin. Monoisotopic peptide $\mathrm{m} / \mathrm{z} 1706.7$ is capable of a mixture of modifications dependent on the experimental set-up.

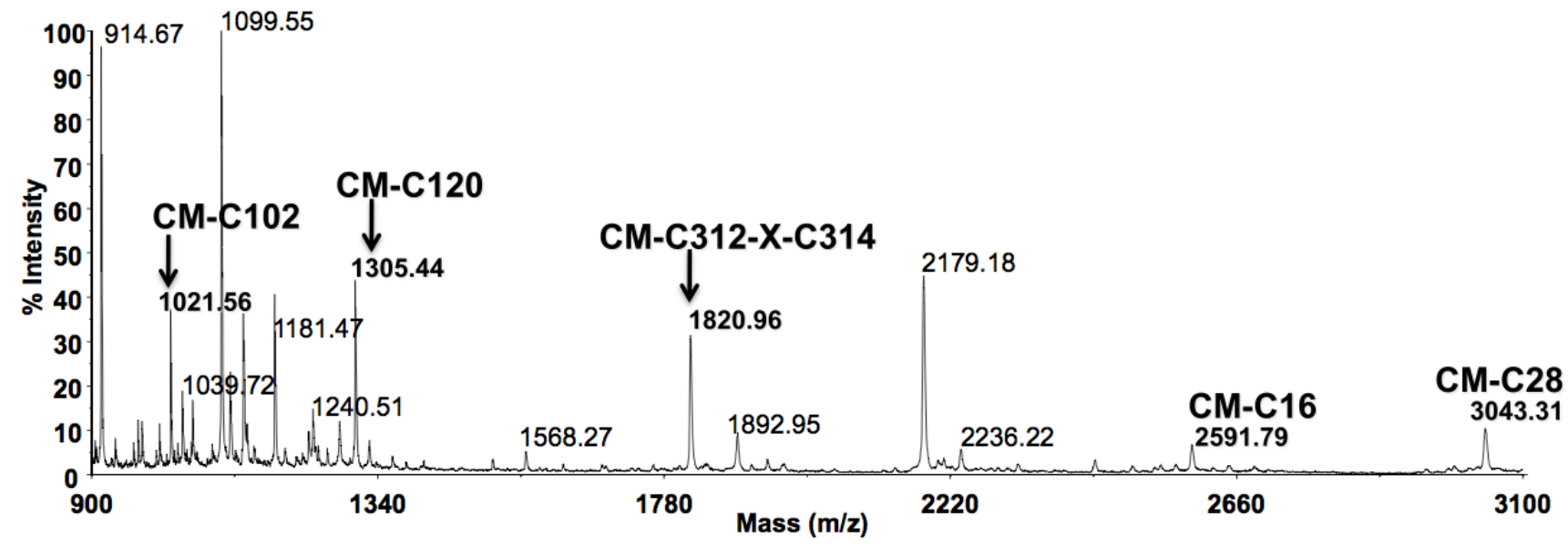

Figure S7. Mass fingerprint of reduced, CM-labeled, Trypsin digested hYVH1 (no AuNPs). Modified thiolcontaining peptides are highlighted, their peptide masses in bold. 


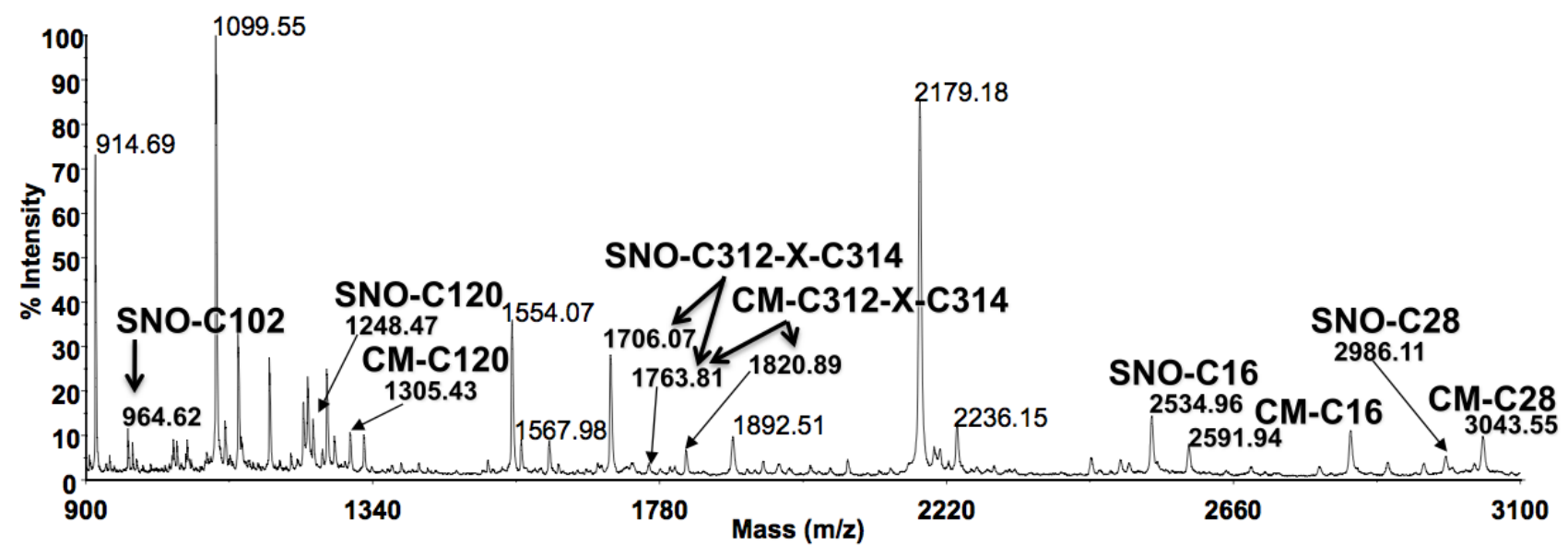

Figure S8. Mass fingerprint of reduced, $S$-nitrosylated, CM-labeled, Trypsin digested hYVH1 (no AuNPs). Modified thiol-containing peptides are highlighted, their peptide masses in bold. 

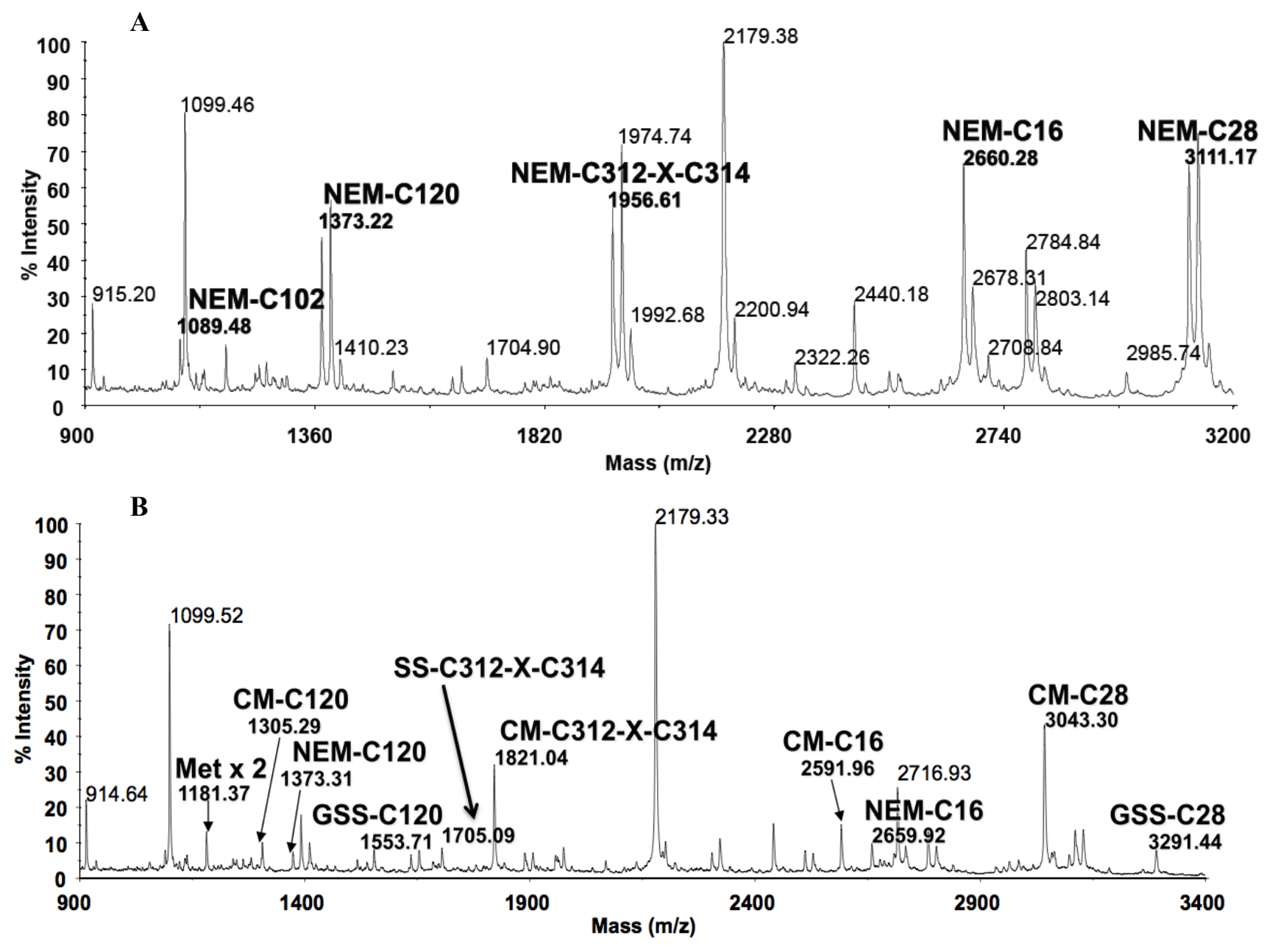

Figure S9. ( $\boldsymbol{A}$ ) Mass fingerprint of reduced, NEM-labeled, Trypsin digested hYVH1 (no AuNPs) (B) Mass fingerprint of reduced, $S$-nitrosylated, CM-labeled, denitrosylated, NEM-labeled, Trypsin digested hYVH1 (no AuNPs). Modified thiol-containing peptides are highlighted, their peptide masses in bold. 


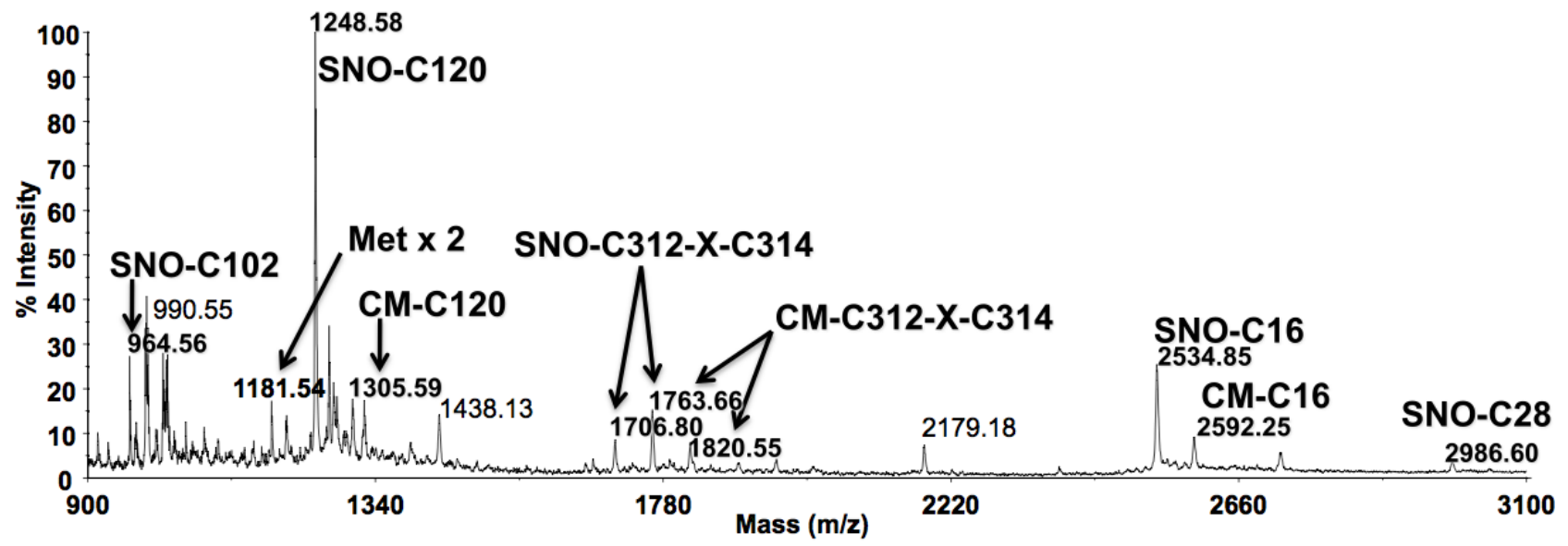

Figure S10. Mass fingerprint of reduced, $S$-nitrosylated, CM-labeled, Trypsin digested, AuNP-bound hYVH1 DTT elution. Modified thiol-containing peptides are highlighted, their peptide masses in bold.

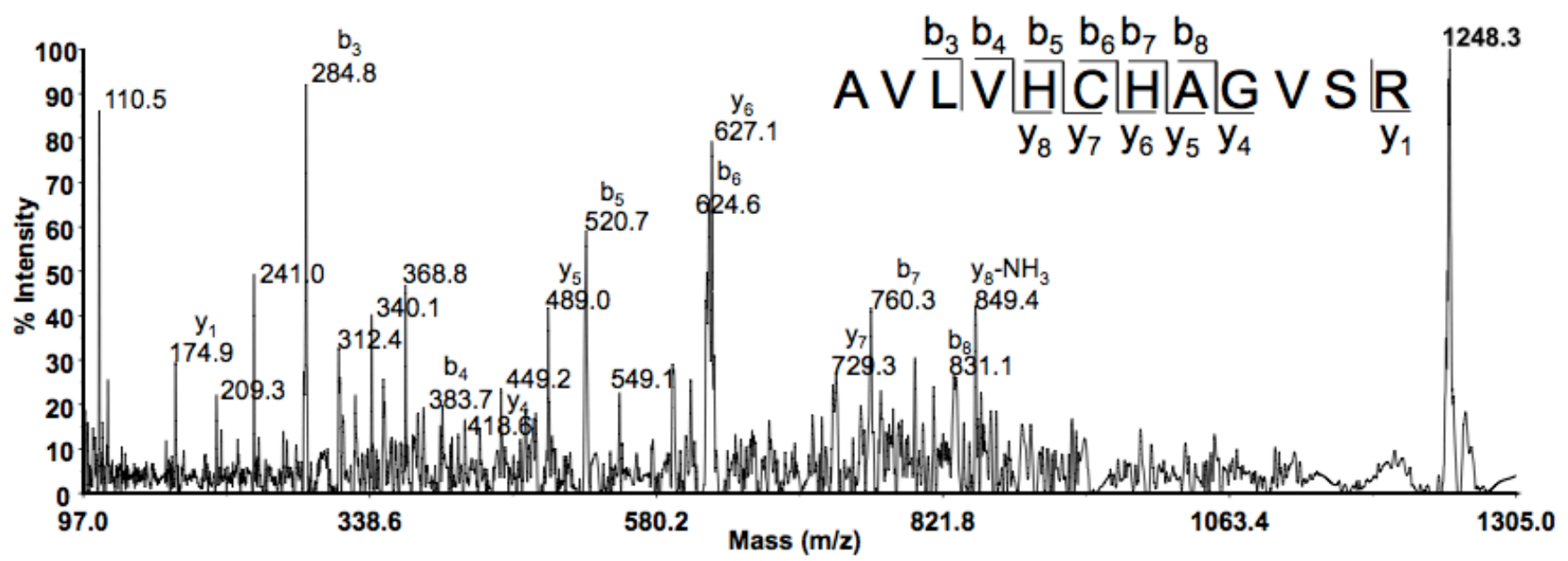

Figure S11. MS/MS analysis of hYVH1 active site parent ion peak $m / z 1248.3$ from reduced, $S$-nitrosylated, CM-labeled, Trypsin digested, AuNP-bound DTT elution sample. 


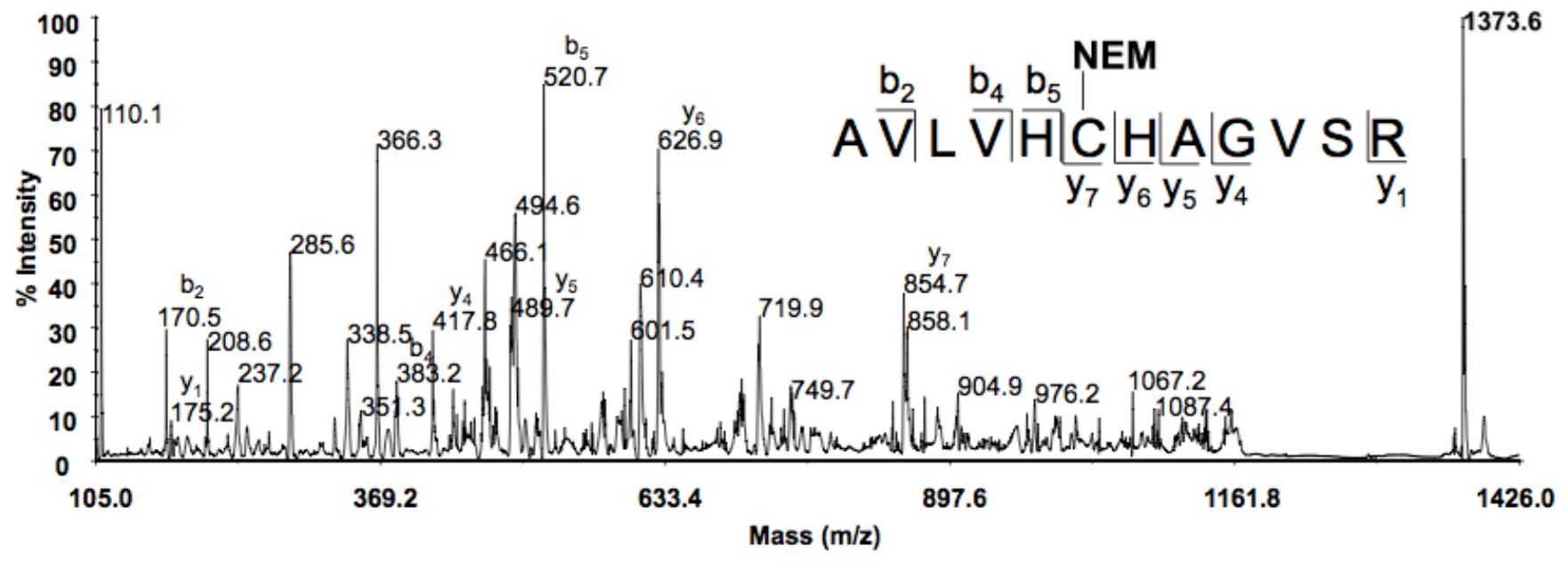

Figure S12. MS/MS analysis of hYVH1 active site parent ion peak $m / z 1373.6$ from reduced, $S$-nitrosylated, CM-labeled, denitrosylated, NEM-labeled, Trypsin digested, AuNP-bound DTT elution sample.

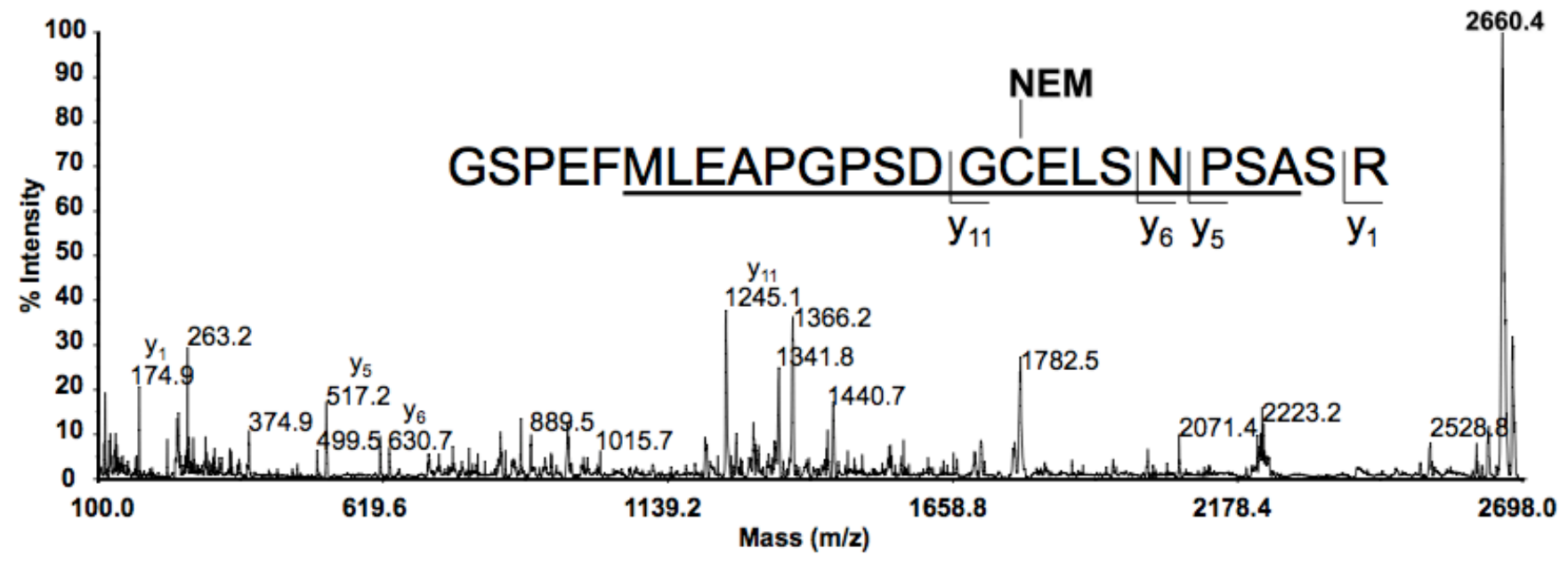

Figure S13. MS/MS analysis of hYVH1 parent ion peak $\mathrm{m} / z 2660.4$ from reduced, $S$-nitrosylated, CM-labeled, denitrosylated, NEM-labeled, Trypsin digested, AuNP-bound DTT elution sample. 


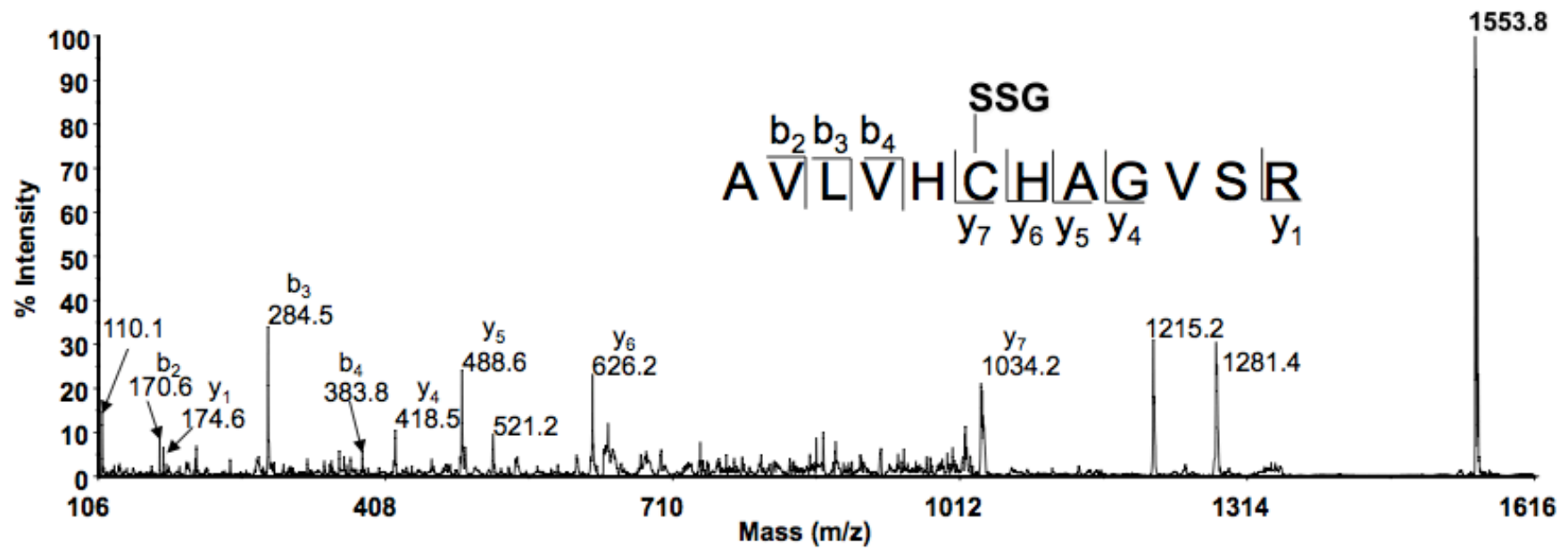

Figure S14. MS/MS analysis of hYVH1 active site parent ion peak $m / z 1553.8$ from reduced, $S$-glutathionylated, CM-labeled, Trypsin digested, pre-AuNP-bound sample.

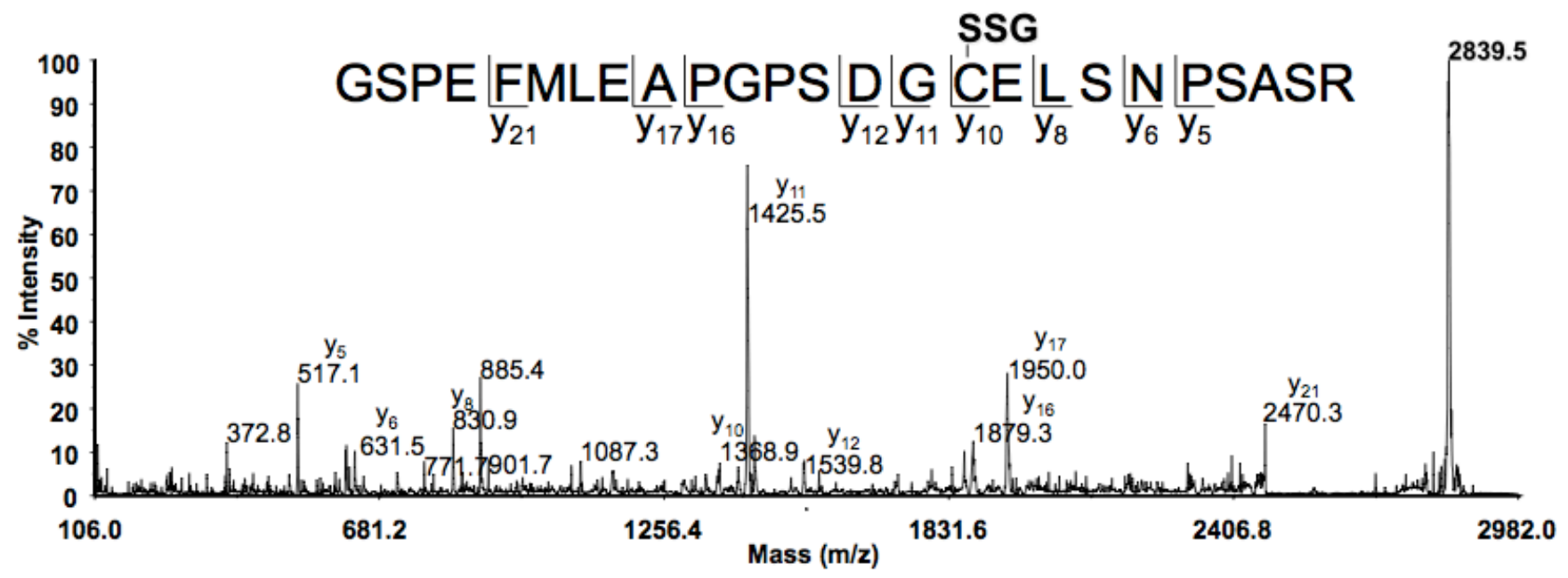

Figure S15. MS/MS analysis of hYVH1 parent ion peak $\mathrm{m} / z 2839.5$ from reduced, $S$-glutathionylated, CMlabeled, Trypsin digested, pre-AuNP-bound sample. 